\title{
When strength turns into disease: acne fulminans in a bodybuilder ${ }^{*}$
}

\author{
Mario Perez ${ }^{1}$ \\ Andrea Antunez-Lay ${ }^{1}$
}

\author{
Lucas Navajas-Galimany ${ }^{1}$ \\ Ariel Hasson ${ }^{1}$
}

DOI: http://dx.doi.org/10.1590/abd1806-4841.20165345

\section{To the Editor:}

A 31-year-old male visited our hospital seeking dermatological care. He had been bodybuilding for a long time and had recently initiated a strict preparation program for a contest. To this end, he took intramuscular testosterone injections on three occasions, developing severe acneiform lesions. The course was gradual but progressive, leading to limitations in his daily activities, with arthralgia of the shoulders and ankles, as well as difficulty to work, move, change clothes and even sleep at night. No fever was reported. Initial testing revealed: a white blood count of 12.570/ $\mathrm{mm}^{3}$; an erythrocyte sedimentation rate of $50 \mathrm{~mm} / \mathrm{h}$; a platelet count of $278.000 / \mathrm{mm}^{3}$, without liver abnormalities. Upon physical examination, multiple, nodulocystic, erythematous papules and pustules were found on his face, chest, back and arms. Extensive ulcerations with brown-yellowish thick crusts were scattered mainly over his shoulders, the proximal areas of both arms and the upper back (Figure 1). The diagnosis of acne fulminans was made and treatment was initiated with prednisone $45 \mathrm{mg}$ / daily, doxycycline $100 \mathrm{mg}$ twice daily and antihistamines. He was told to definitively discontinue hormonal treatment. Four weeks later, isotretinoin was started at an initial dose of $30 \mathrm{mg} /$ daily and corticosteroids were gradually tapered. A good clinical response was achieved, with progressive healing. Acne fulminans is a rare condition, considered the most severe form of acne. ${ }^{1}$ It usually affects young individuals aged 13-22 years, predominantly males with a prior history of mild or moderate $a_{c n} e^{2}$. It is characterized by the sudden onset of highly inflammatory, ulcerative, painful lesions covered with haemorrhagic crusts, most often located on the upper chest and back. ${ }^{2}$ Constitutional symptoms and laboratory abnormalities are frequently seen, as in this case. The etiology of acne fulminans remains unclear but it appears to be multifactorial. Doping acne is a variant, induced by exogenous hormones (EHs) such as testosterone or derivatives, provoking hypertrophy of the sebaceous glands, increased production of skin surface lipids and sebum, in addition to increased density of the Propionibacterium acnes population. ${ }^{3,4}$ The prevalence of $\mathrm{EH}$ usage is increasing dramatically, especially among amateur

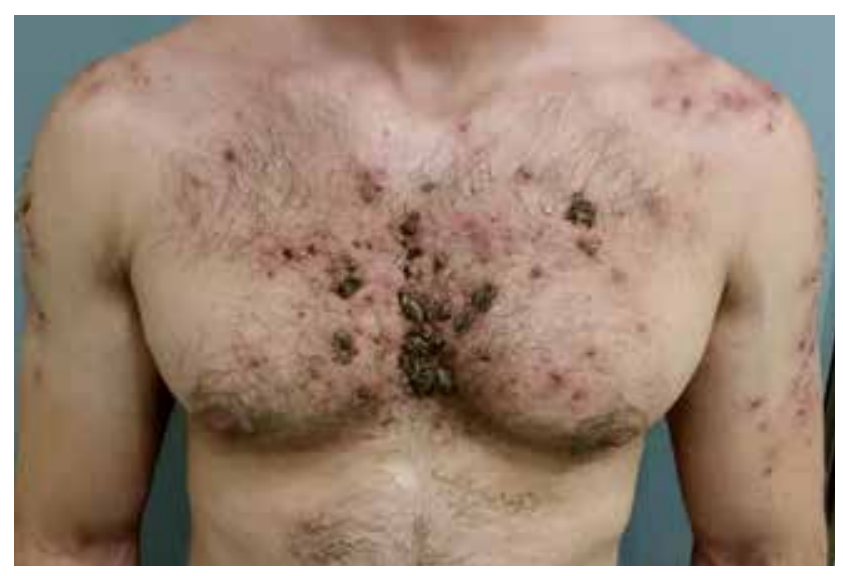

Figure 1: Multiple erythematous nodules, papules, pustules and ulcerations with brown-yellowish thick crusts on the chest, shoulders and arms

bodybuilders (reaching up to $80 \%$ ) and weightlifters (38-58\%). This is favored by the non-therapeutic prescription of EH by some physicians who are unaware of its side effects. It has been estimated that up to $50 \%$ of users could develop doping acne. ${ }^{3}$ Certainly, the most important indication in these cases is the immediate cessation of EH. Due to severe, systemic symptoms, supportive care, along with a 4-6 week course of systemic corticosteroids, must be considered as first-line therapy. Subsequent addition of systemic retinoids is recommended, starting with $0.5 \mathrm{mg} / \mathrm{kg}$ daily, with a gradual dose increase to achieve early control of constitutional features as well as clearance of lesions. ${ }^{5}$ It is imperative nowadays to pay special attention to society's growing interest in having a perfectly sculpted body. Acne is a condition commonly associated with the use of hormonal therapies and its severe forms represent one of the risks that must be diagnosed and treated promptly. $\square$

Received on 07.11.2015

Approved by the Advisory Board and accepted for publication on 16.12.2015

Work performed at the Department of Dermatology. Facultad de Medicina. Pontificia Universidad Católica de Chile - Santiago, Chile.

Conflict of Interest: None.

1 Pontificia Universidad Católica de Chile - Santiago, Chile.

C2016 by Anais Brasileiros de Dermatologia 


\section{REFERENCES}

1. Giavedoni P, Mascaró-Galy JM, Aguilera P, Estrach-Panella T. Acne fulminans successfully treated with cyclosporine and isotretinoin. J Am Acad Dermatol. 2014;70:e38-9.

2. Zaba R, Schwartz R, Jarmuda S, Czarnecka-Operacz M, Silny W.. Acne fulminans: explosive systemic form of acne. J Eur Acad Dermatol Venereol. 2011;25:501-7.

3. Walker J, Adams B. Cutaneous manifestations of anabolic-androgenic steroid use in athletes. Int J Dermatol. 2009;48:1044-8.

4. Kraus SL, Emmert S, Schön MP, Haenssle HA. The dark side of beauty: acne fulminans induced by anabolic steroids in a male bodybuilder. Arch Dermatol. 2012;148:1210-2.

5. Lages RB, Bona SH, Silva FV, Gomes AK, Campelo V. Acne fulminans successfully treated with prednisone and dapsone. An Bras Dermatol. 2012;87:612-4.
MAILING ADDRESS:

Lucas Navajas-Galimany

Av. Vicuña Mackenna 4686. Santiago, Chile.

E-mail:lfnavaja@uc.cl

How to cite this article: Perez M, Navajas-Galimany L, Antunez-Lay A, Hasson A. When strength turns into disease: acne fulminans in a bodybuilder. An Bras Dermatol. 2016;91(5):706-7. 